\title{
EDITORIAL
}

\section{The need for antituberculosis drug resistance surveillance in Europe}

\author{
R. Loddenkemper
}

As tuberculosis (TB) incidence and prevalence are increasing dramatically in most parts of Eastern Europe together with a steep rise in resistance against the first-line TB drugs in these countries [1, 2], it is becoming even more interesting to evaluate this development in more detail and to see in addition what its impact is on lowincidence countries. In particular, multidrug resistance, which by definition is combined resistance against at least the two most powerful drugs, isoniazid (INH) and rifampicin, is both of general public interest, since it may interfere with the future control of TB, and of interest to the individual patient, since a cure may not be achieved due to a lack of efficient drugs for treatment.

It is currently a matter of debate as to how this problem of multidrug-resistant (MDR) TB should be tackled in the future, since the common directly observed treatment, short course (DOTS) strategy recommends TB treatment with the four first-line drugs INH, rifampicin, ethambutol and streptomycin, which may fail [3]. Therefore, the "DOTS Plus" programme has been proposed, which is composed of two different approaches, one based on treatment with second-line drugs in high-risk groups and the other based on the results of susceptibility tests and the use of drugs according to these test results [4].

That the problem really exists is underlined by the publication of the results of "Surveillance of antituberculosis drug resistance in Switzerland 1995-1997: the central link" in this issue of the European Respiratory Journal [5]. Of 956 culture-positive TB complex cases, 66 (6.3\%) patients carried a strain resistant to at least one of the first-line drugs INH, rifampicin, ethambutol and pyrazinamide. Susceptibility results for streptomycin were not included, although resistance to streptomycin can be as high as to $\mathrm{INH}$, in particular in patients from Eastern Europe [6]. Sixty patients carried a strain at least resistant to INH, 17 to rifampicin, 11 to pyrazinamide and seven to ethambutol. More than two-thirds of these patients were born abroad (being mostly males and young persons, who also had a history of previous anti-TB treatment; these were the most important risk factors). Fourteen (1.8\%) cases of MDR-TB were notified; 13 of them were foreign-born. Only two originated from Eastern Europe, but this will certainly vary from country to country, i.e., in Germany, 43.1\% of all MDR cases 1996-1998 were from Eastern

Correspondence: R. Loddenkemper, Lungenklinik Heckeshorn, Zum Heckeshorn 33, D-14109 Berlin, Germany. Fax: 493080022286.
Europe [6]. This is the first published report on an anti-TB drug resistance national surveillance system with routine linking of all clinical and routine laboratory information of all notified cases. It proves that this surveillance system functions, at least in Switzerland, which is highly developed and also a small country, which facilitates data collection.

In order to achieve similar surveillance results in all other European countries, the second paper, on anti-TB drug resistance surveillance in Europe, published in this issue proposes standards for drug resistance surveillance [7]. This paper on "Standardization of anti-TB drug resistance surveillance in Europe" is in line with a number of recommendations on TB surveillance in Europe published in the European Respiratory Journal since 1991 by the Working Group of the World Health Organization (WHO) and the International Union against Tuberculosis and Lung Disease (IUATLD). The first report aimed very ambitiously at "Tuberculosis Elimination in the countries of Europe and other industrialized countries" [8].

The second report, on "Tuberculosis control in Europe and international migration", was published in 1994, when the problem of universally accepted definitions had become apparent, in particular regarding case definitions, which hampered further analysis of TB control in relation to international migration in Europe [9]. Common principles for the surveillance of TB in European countries were therefore developed for a minimum of necessary data. This was achieved by a working group report on "Surveillance of tuberculosis in Europe", which gave consensus-based recommendations for uniform reporting of TB surveillance data in the countries of Europe, as it had been realized that a lack of definitions among the various countries made comparisons difficult [10]. This report provided the basis for data collection in Europe, started by EuroTB [11] as well as by the WHO European Region office, which it is intended to be harmonized in the near future.

The next step, in 1998, was the development of proposals for criteria for the analysis of treatment results in different European countries, as, again, it had become apparent that monitoring systems for reporting treatment outcome did not exist or were not mandatory in Europe (with the exception of Norway) [12]. Definitions for cure, treatment completed, treatment failure and death, retreatment cases, and chronic cases were described, including a short form for minimal information on individual TB cases. These data were intended not only for comparison 
of the situation in different European countries but also for evaluation of the effectiveness of interventions.

A preliminary report on treatment outcome was presented during the first conference of the European Region of the IUATLD in Budapest, which already included 23 countries (personal communication, J. Veen). Although this kind of data collection certainly needs some refinements in the future, it made analysis of faults and drawbacks possible, which should be helpful in solving problems, including the recognition of underlying causes of treatment and retreatment failure. In addition, it should allow better evaluation of the causes leading to the resurgence of TB in some low-incidence countries in Europe, although this is mainly due to TB in the foreign-born, intravenous drug users and socially marginalized individuals $[13,14]$. In 1999, recommendations for "Tuberculosis management in Europe" were published in the European Respiratory Journal by a task force in which the European Respiratory Society, for the first time, cooperated directly with the WHO and the Europe Region of the IUATLD. These guidelines were particularly focused on standardized anti-TB treatment, treatment result monitoring and treatment in special situations [15].

Based on the guidelines for surveillance of drug resistance in TB published by the WHO and IUATLD in 1996, which included proposals for general principles and standard methods [16], the new recommendations propose further data for collection, since major factors associated with drug-resistant TB in Europe, such as migration and the age of TB patients, are not yet taken into account appropriately. The report also includes a survey of antiTB drug susceptibility testing practices and surveillance systems in 47 countries of the WHO European Region for 1998 [7]. However, it would seem doubtful that all countries which claim drug susceptibility testing in $>90 \%$ of cases really perform these, in particular those countries not participating in international proficiency testing. These recommendations not only define the different kinds of drug resistance but also recommend indicators which should be used for surveillance of drug resistance, as well as commenting on the laboratory methods to be used.

It is hoped that all of these proposals for standardization will prove helpful in setting up appropriate tuberculosis control measures necessary for the successful fight against tuberculosis.

\section{References}

1. Raviglione MC, Rieder HL, Styblo K, Khomenko AG, Esteves K, Kochi A. Tuberculosis trends in Eastern Europe and the former USSR. Tuberc Lung Dis 1994; 75: 400-416.

2. World Health Organization. Global tuberculosis control. WHO report 1998; WHO/TB/98.237. Geneva, World Health Organization, 1998.

3. Farmer PE. Managerial successes, clinical failures. Int $J$ Tuberc Lung Dis 1999; 3: 365-367.

4. Espinal MA, Dye C, Raviglione MC, Kochi A. Rational "DOTS Plus" for the control of MDR-TB. Int J Tuberc Lung Dis 1999; 3: 561-563.

5. Helbling P, Altpeter E, Raeber P-A, Pfyffer GE, Zellweger JP. Surveillance of antituberculosis drug resistance in Switzerland 1995-1997: the central link. Eur Respir J 2000; 16: 200-202.

6. Forssbohm M. Studie des DZK zur Epidemiologie der Tuberkulose. In: Deutsches Zentralkomitee zur Bekämpfung der Tuberkulose. 25. Informationsbericht 1999, Frankfurt am Main, Pmi Verlag AG, 2000; pp. 92-105.

7. Schwoebel V, Lambregts-van Weezenbeek CSB, Moro M-L, et al. Standardization of antituberculosis drug resistance surveillance in Europe. Recommendations of a World Health Organization (WHO) and International Union Against Tuberculosis and Lung Disease (IUATLD) Working Group. Eur Respir J 2000; 16: 364-371.

8. Clancy L, Rieder HL, Enarson DA, Spinaci S. Tuberculosis elimination in the countries of Europe and other industrialized countries. Based on a workshop held at Wolfheze, Netherlands, 4-9 March 1990, under the joint auspices of the IUATLD (Europe region) and WHO. Eur Respir J 1991; 4: 1288-1295.

9. Rieder HL, Zellweger J-P, Raviglione MC, Keizer ST, Migliori GB. Tuberculosis control in Europe and international migration. Report of a European Task Force. Eur Respir J 1994; 7: 1545-1553.

10. Rieder HL, Watson JM, Raviglione MC, et al. Surveillance of tuberculosis in Europe. Recommendations of a Working Group of the World Health Organization (WHO) and the European Region of the International Union Against Tuberculosis and Lung Disease (IUATLD) for uniform reporting on tuberculosis cases. Eur Respir $J$ 1996; 9: 1097-1104.

11. EuroTB (CESES/KNCV) and the national coordinators for tuberculosis surveillance in the WHO European region. Surveillance of tuberculosis in Europe. Report on tuberculosis cases notified in 1997. 1999.

12. Veen J, Raviglione M, Rieder HL, et al. Standardized tuberculosis treatment outcome monitoring in Europe. Recommendations of a Working Group of the World Health Organization (WHO) and the European Region of the International Union Against Tuberculosis and Lung Disease (IUATLD) for uniform reporting by cohort analysis of treatment outcome in tuberculosis patients. Eur Respir J 1998; 12: 505-510.

13. Borgdorff MW, Nagelkerke N, Van Soolingen D, De Haas PE, Veen J, Van Embden JDA. Analysis of tuberculosis transmission between nationalities in the Netherlands in the period 1993-1995 using DNA fingerprinting. Am J Epidemiol 1998; 147: 187-195.

14. Bauer J, Kok-Jensen A, Faurschou P, Thuesen J, Taudorf E, Andersen $\AA$ B. A prospective evaluation of the clinical value of nation-wide DNA fingerprinting of tuberculosis isolates in Denmark. Int J Tuberc Lung Dis 2000; 4: 295299.

15. Migliori GB, Raviglione MC, Schaberg T, et al. on behalf of the Task Force of ERS, WHO and the Europe Region of IUATLD. Tuberculosis management in Europe. Recommendations of a Task Force of the European Respiratory Society (ERS), the World Health Organization (WHO) and the International Union against Tuberculosis and Lung Disease (IUATLD) Europe Region. Eur Respir $J$ 1999; 14: 978-992.

16. World Health Organization, International Union Against Tuberculosis and Lung Disease. Guidelines for surveillance of drug resistance in tuberculosis. WHO/TB/ 96.216. Geneva, World Health Organization 1996. 